\title{
MAPEAMENTO DAS UNIDADES DE FORMAÇÃO ACADÊMICA - UFAS REGIÃO SUL II
}

Francisca Rodrigues de Oliveira Pini ${ }^{1}$ Ana Lívia Adriano ${ }^{2}$

\section{RESUMO}

A pesquisa "Mapeamento das Unidades de Formação Acadêmica - UFAs Região Sul II”, realizada pela Associação Brasileira de Ensino e Pesquisa em Serviço Social (ABEPSS), na gestão 2009-2010, apresenta a intencionalidade de compreender as particularidades da formação profissional do assistente social, no que tange ao perfil das UFAs, a organização curricular, a relação com a ABEPSS, o estágio supervisionado, a pesquisa e as estratégias para afirmação das Diretrizes Curriculares na formação profissional. Apreender as particularidades da profissão, sua formação e exercício profissional, articulando-os, necessariamente, às determinações históricas em que estes estão inseridos, torna-se condição para a afirmação do projeto profissional, seus princípios, valores e lutas, bem como para a afirmação do significado social da profissão enquanto especialização do trabalho coletivo, que tem como objeto de intervenção as múltiplas expressões da questão social e os sujeitos que convivem com a exploração, a injustiça e a negação da dignidade humana.

PALAVRAS-CHAVE: Formação profissional, Diretrizes Curriculares; Exercício Profissional, Serviço Social

\footnotetext{
${ }^{1}$ Assistente social, mestre e doutora em Políticas Sociais e Movimentos Sociais pela PUC/SP, diretora Pedagógica do Instituto Paulo Freire, coordenadora do Curso de Serviço Social da Faculdade de Mauá e professora do Observatório Regional de Políticas Públicas e Movimentos Sociais na mesma Faculdade, filiada a ANDHEP e vice-presidente da ABEPSS Sul II- Gestão 2011-2012. E-mail: franpini@paulofreire.org.

${ }^{2}$ Assistente social, mestre e doutoranda em Serviço Social pela PUC/SP, professora da Faculdade de Mauá/SP. E-mail: analiviass@gmail.com.
} 


\section{BREVES CONSIDERAÇÕES}

Este relatório analítico consiste numa sistematização dos dados obtidos pela pesquisa "Mapeamento das Unidades de Formação Acadêmica - UFAs Região Sul II", realizada pela Associação Brasileira de Ensino e Pesquisa em Serviço Social (ABEPSS), na gestão 2009-2010.

Apresenta a intencionalidade de compreender as particularidades da formação profissional do assistente social, no que tange ao perfil das UFAs, a organização curricular, a relação com a ABEPSS, o estágio supervisionado, a pesquisa e as estratégias para afirmação das Diretrizes Curriculares na formação profissional.

Apreender as particularidades da profissão, sua formação e exercício profissional, articulando-os, necessariamente, às determinações históricas em que estes estão inseridos, torna-se condição para afirmação do projeto profissional, seus princípios, valores e lutas, bem como para a afirmação do significado social da profissão, enquanto especialização do trabalho coletivo que tem como objeto de intervenção as múltiplas expressões da questão social e os sujeitos que convivem com a exploração, a injustiça e a negação da dignidade humana.

As demandas contemporâneas postas ao exercício profissional do assistente social requer uma formação profissional crítica que possibilite a apreensão da questão social, suas bases históricas, formas de se expressar no cotidiano da vida social e estratégias de enfrentamento. Requer, necessariamente, uma estreita vinculação entre os temas e questões candentes e a possibilidade de crítica para o enfrentamento da precarização das relações de trabalho, a perda de direitos sociais, a fragmentação das lutas da classe trabalhadora, a mínima relação Estado/Sociedade Civil, a terceirização, a subcontratação etc., entendendo que "a sintonia da formação profissional com o Revista Serviço Social \& Saúde. UNICAMP Campinas, v. X, n. 11, Jul. 2011 
mercado de trabalho é a condição para se preservar a própria sobrevivência do Serviço Social" (IAMOMOTO, 1998, p. 172).

$\mathrm{O}$ avanço da robótica e da tecnologia redesenha padrões de produção e consumo, globaliza os mercados, exige do trabalhador maior flexibilidade, qualificação da mão de obra e, nessa direção, a propalada ascensão do neoliberalismo apresenta-se como a única forma de interpretação do mundo capaz de dar conta desta nova fase da sociedade, normalmente chamada de globalização. Ao afirmar a racionalidade do mercado e a capacidade que este tem de organizar a vida social, a ideologia neoliberal introduz a ideia de competição e competitividade e utiliza-se das ideias denominadas "pós-modernas" para negar as ideias de razão, universalidade, consciência, história, classes e

[...] afirmar como realidades únicas e últimas a superfície veloz do aparecer social, a intimidade e a privacidade narcísicas, expostas publicamente sob a forma da propaganda e da publicidade, a competição e a vitória individual a qualquer preço (CHAUí, 2004, p. 45).

A velocidade das mudanças científicas e tecnológicas exige uma universidade operacional (CHAUI, 2004), que privilegie uma formação tecnicista, mecanizada, aligeirada em que o exercício da crítica e da criação são absolutamente dispensáveis. A proposta de privatização das universidades públicas, a redução da carga horária e do tempo de formação dos cursos de graduação, maior otimização da tecnificação para uma rápida absorção do mercado, a dissolução entre ensino-pesquisa-extensão, o incentivo e investimento na abertura de faculdades isoladas, de caráter privado e as formas burocratizadas de avaliação dos cursos, das Unidades de Ensino, do corpo discente e docente rebatem diretamente na formação profissional do assistente social. 
Tal cenário nos convida a construir coletivamente estratégias de enfrentamento para o fortalecimento dos pressupostos da formação profissional do assistente social colocado nas Diretrizes Curriculares e, nessa perspectiva, a ABEPSS, enquanto entidade político-científica coloca-se como protagonista dessa luta, em conjunto com as UFAs, docentes e discentes, cujas particularidades estarão esboçadas nesta pesquisa, cujo desafio maior é confrontar o real no seu particular, para apreender a totalidade.

\section{Identificação das Instituições que participaram da pesquisa}

Conforme assinalada anteriormente, essa pesquisa teve como sujeito todas as UFAs da região Sul II (São Paulo e Mato Grosso do Sul), sendo enviados questionários e convites a todas as escolas de Serviço Social desta região que tem ensino em modalidade presencial. O instrumental foi construído pela diretoria da ABEPSS Região Sul II em conjunto com os docentes, discentes e supervisores de campo das UFAs e teve como responsável pela sistematização e análise dos dados as professoras Francisca Rodrigues Pini e Ana Lívia Adriano, da Faculdade de Mauá (Fama).

De um universo de 66 Cursos de Serviço Social, somente 23 UFAs fizeram a devolutiva do questionário, cuja sistematização inicial foi apresentada na Oficina Regional da ABEPSS Região Sul II, que ocorreu em novembro de 2010, na Universidade Federal de São Paulo - Campus Baixada Santista.

Apresentamos a seguir as instituições que participaram da pesquisa: 


\section{Quadro 1- INSTITUIÇÕES PARTICIPANTES DA PESQUISA}

\begin{tabular}{|c|c|}
\hline $\begin{array}{l}\text { 1) Centro Universitário da Fundação Educacional de } \\
\text { Barretos - Unofeb } \\
\text { Av. Prof. Roberto Frade Monte, Bairro Aeroporto - } \\
\text { Barretos/SP 14780-000 } \\
\text { (17) } 3321-6411 \text { / www.feb.br }\end{array}$ & $\begin{array}{l}\text { 2) União das Faculdades dos Grandes Lagos - Unilago } \\
\text { Rua Eduardo Nielsen, } 960 \text { - São José do Rio Preto/SP } \\
\text { 15070-030 - (17) } 3354-6061 \text { / unilago@unilago.com.br }\end{array}$ \\
\hline $\begin{array}{l}\text { 3) Centro Universitário de Votuporanga - Unifev } \\
\text { Rua Pernambuco, } 4196 \text { - Votuporanga/SP - 15500- } \\
000 \text { - (17) 3405-9999 jjosiani@bol.com.br }\end{array}$ & $\begin{array}{l}\text { 4) Universidade Camilo Castelo Branco - Unicastelo } \\
\text { Rua Carolina Fonseca, } 584 \text { - Itaquera - São Paulo/SP } \\
08230-030 \quad-\quad \text { (11) } \\
\text { coord.servsocial.sp@ unicastelo.br }\end{array}$ \\
\hline $\begin{array}{l}\text { 5) Faculdade de Serviço Social PUC-Campinas } \\
\text { Rodovia D. Pedro I, Km } 136 \text { - Campinas/SP } \\
\text { 13086-900 - (19) 3343-7019 } \\
\text { fss.cchsa@puc-campinas.edu.br }\end{array}$ & $\begin{array}{l}\text { 6) Faculdade de Mauá - Fama } \\
\text { Rua Vitorino Dell' Antonia, } 349 \text { - Vila Noemia } \\
\text { Mauá/SP 09370-570 - (11) 4512-6100 } \\
\text { servicosocial@facmaua.edu.br }\end{array}$ \\
\hline $\begin{array}{l}\text { 7) Faculdade de Serviço Social de Bauru } \\
\text { Pça IX de Julho 1-51 - Vila Pacífico - Bauru } \\
\text { 17050-790 - (14) } 21075060 \\
\text { socialdepto@ite.edu.br }\end{array}$ & $\begin{array}{l}\text { 8) Universidade Estadual Paulista (Unesp) Campus de } \\
\text { Franca. Faculdade de História, Direito e Serviço Social. } \\
\text { Av. Eufrázia Monteiro Petráglia, } 900 \text { - Franca/SP } \\
\text { 14409-160 - (16) 3706-8897 mdss@,franca.unesp.br } \\
\underline{\operatorname{ccg} @ \text { franca.unesp.br }}\end{array}$ \\
\hline $\begin{array}{l}\text { 9) Faculdades Integradas de Fernandópolis - Fife - } \\
\text { Fundação Educacional de Fernandópolis/FEF } \\
\text { Av. Teotônio Vilela, s/n, Campus Universitário - } \\
\text { Fernandópolis/SP } \\
\text { 15600-000/ (17) 3465-0000 www.fef.br }\end{array}$ & $\begin{array}{l}\text { 10) Universidade Federal de São Paulo - Campus } \\
\text { Baixada Santista/Unifesp-BS } \\
\text { Av. Almirante Saldanha da Gama, no } 89 \text { - Ponta da } \\
\text { Praia-Santos/SP 11030-400 - (13) 3261-3324 } \\
\text { orma.braz@,unifesp.br }\end{array}$ \\
\hline $\begin{array}{l}\text { 11) Faculdades Integradas Maria Imaculada } \\
\text { Rua Maringá, } 450 \text { - Parque Taquaral - Piracicaba/SP } \\
\text { 13423-514 - (19) 3414-2003 } \\
\text { servicosocial@mariaimaculada.br }\end{array}$ & $\begin{array}{l}\text { 12) Centro Universitário de Jales - Unijales } \\
\text { Av. Francisco Jalles, } 1451 \text { - Centro - Jales/SP } \\
\text { 15700-000-(17) 3622-1620 } \\
\text { unijales@edu.com.br }\end{array}$ \\
\hline $\begin{array}{l}\text { 13) ISCA Faculdades } \\
\text { Via 147, Limeira-Piracicaba Km } 4 \text { - Cruz do Padre - } \\
\text { Limeira/SP - 13482-383 - (19) 3404-4735 } \\
\text { paulabocaiuva@gmail.com / coordsocial@alie.br }\end{array}$ & $\begin{array}{l}\text { 14) Curso de Serviço Social da Unilins } \\
\text { Av. Nicolau Zarvos, } 1925 \text { - Lins/SP } \\
\text { 16400-000-(14) 3533-3200 } \\
\text { lcmontanha@unilins.edu.br }\end{array}$ \\
\hline $\begin{array}{l}\text { 15) Centro Universitário Nossa Senhora do } \\
\text { Patrocínio Itu / Salto - Faculdade de Gestão e } \\
\text { Hospitalidade - Rua dos Andradas s/n - Centro - } \\
\text { Itu/SP 13300-000 - (11) 4013-9900 } \\
\text { marisa.souza@coord.ceusnp.edu.br }\end{array}$ & $\begin{array}{l}\text { 16) Curso de Serviço Social da Universidade Católica } \\
\text { de Santos } \\
\text { Av. Conselheiro Nébias, } 300 \text { - Santos/SP 11015-002 - } \\
\text { (13) 3205-5555 - ramal } 1328 \text { / coord.ss@unisantos.br }\end{array}$ \\
\hline
\end{tabular}




\begin{tabular}{|c|c|}
\hline $\begin{array}{l}\text { 17) Faculdade Paulista de Serviço Social - } \\
\text { FAPSS/SP } \\
\text { Rua Lopes Chaves, } 273 \text { - Barra Funda - São } \\
\text { Paulo/SP - 01154-010 - (011) 3666-0246 } \\
\text { fapss@,fapss.br }\end{array}$ & $\begin{array}{l}\text { 18) Universidade de Marília } \\
\text { Avenida Higino Muzzy Filho, } 1001 \text { - Marília/SP } \\
\text { 17525-970 - (DDD) 2105-4012 } \\
\text { humanas.malves@unimar.br }\end{array}$ \\
\hline $\begin{array}{l}\text { 19) Universidade do Vale do Paraíba - Univap - } \\
\text { Curso de Serviço Social } \\
\text { Av. Shishima Hifumi, } 2911 \text { - Urbanova - São José } \\
\text { dos Campos SP 12244-000 - (12) 3947-1015 } \\
\text { gpaiva@,univap.br }\end{array}$ & $\begin{array}{l}\text { 20) Universidade de Ribeirão Preto - Unaerp - Campus } \\
\text { Guarujá - Av. Dom Pedro, } 3300 \text { - Enseada -Guarujá } \\
\text { 11440-003 - (013) 3398-1058 / jlins@ unaerp.br }\end{array}$ \\
\hline $\begin{array}{l}\text { 21) Faculdade de Mirandópolis - FAM } \\
\text { Avenida São Paulo, } 965 \text { - Bairro Nogara } \\
\text { Mirandópolis/SP 16800-000 } \\
\text { (18) 3701-1101 (18) 3701-4727 / } \\
\text { shizuko.miguita@,uniesp.edu.br } \\
\text { ana.santos@uniesp.edu.br }\end{array}$ & $\begin{array}{l}\text { 22) Faculdades Metropolitanas Unidas - FMU } \\
\text { Rua Taguá, } 150 \text { - Liberdade - São Paulo/SP - (11) } \\
3209-0684 \text { servico_social@,fmu.br }\end{array}$ \\
\hline $\begin{array}{l}\text { 23) Faculdades Adamantinenses Integradas } \\
\text { Rua } 9 \text { de julho, } 730 \text { - Adamantina } \\
\text { 17800-000 } \\
\text { (18)9711-3860 (18) 3502-7010 / } \\
\text { tan_martins@uol.com.br, fai@,fai.com.br }\end{array}$ & \\
\hline
\end{tabular}

No que tange a natureza das UFAs $14 \%$ são públicas e $86 \%$ privadas, sendo $44 \%$ privadas, $35 \%$ filantrópicas e $17 \%$ comunitária e confessional. Tais dados expressam a mercadologização do ensino superior, mas também a formação das universidades públicas no país, marcada por um viés elitista, de restrita acessibilidade à classe trabalhadora e que se constituiu como formação para a burguesia, reprodução da ideologia desta classe.

Assim, a dimensão de modernização e socialização da cultura que também a universidade proporciona está aliada a ideia neoliberal de que é necessário expandir a acessibilidade da educação superior e formar profissionais preparados para o mercado de trabalho, fazendo com que a educação deixe de ser uma preparação para a vida e 
torne-se educação durante toda a vida, devido às exigências do mercado e constante atualização das informações (CHAUI, 2004). A flexibilização, como a possibilidade de diversificação dos tipos de instituições, dos cursos e currículos, das formas de ingresso no ensino superior coadunam com um controle centralizado que se exerce por meio de uma série de estratégias, como o Exame Nacional de Cursos, o recredenciamento periódico das instituições, a Educação a Distância, medidas essas que são justificadas em função da melhoria qualitativa do ensino.

Recorrendo aos dados apresentados pela pesquisa vemos que nas UFAs 44\% dos cursos possuem de 01-10 anos de existência, 22\% de 31-40 anos, $18 \%$ de 41-50 anos, $4 \%$ de 11-20 anos e 4\% de 60-70 anos. Tais dados apresentam uma particularidade do Serviço Social no Estado de São Paulo, por se constituir o cenário de construção da primeira escola de Serviço Social no Brasil, de natureza confessional e católica - cujo poder da Igreja na formação destes profissionais se configura como um objeto a ser desvelado -, mas também demonstra as artimanhas da reforma do ensino superior no país, a medida que entende que o ensino superior deve ser concedido a quem tiver meios para assegurá-lo, não como direito de todos. O modelo de homem neoliberal é o cidadão privatizado, o enterpreneur, o consumidor (GENTILI, 1996, p. 20-1).

Os dados concernentes à modalidade do curso apontam $96 \%$ dos cursos de modalidade presencial e 4\% semipresencial. Tais indicadores podem sinalizar a luta da categoria profissional e os enfrentamentos políticos e institucionais de discentes e docentes das UFAs para assegurar uma formação de qualidade e não ceder a lógica de organização precarizada do ensino superior.

Os números de alunos apresentados na pesquisa variam de 80 a 400, sendo que $45 \%$ das UFAs possuem de 100 a 200 alunos, $21 \%$ de 200 a 300 alunos, $14 \%$ 
menos de 100 alunos e $4 \%$ de 300 a 400 . A forma de funcionamento dos cursos são, em sua maioria, noturno (73\%), seguido de $17 \%$ matutino/noturno, $5 \%$ vespertino/noturno e $5 \%$ matutino. Tais dados revelam um perfil de discente trabalhador, que compõe uma jornada tripla de trabalho-estudo-responsabilidades da vida privada. Grande parte deste universo está fora da escola há algum tempo, outros saíram de um ensino médio com lacunas, sendo movidos pelo grande desejo e responsabilidade de aprender e ascender pessoal e profissionalmente.

No entanto, há que se considerar a relevância dos dados que a pesquisa apresenta quanto à organização do movimento estudantil nas escolas, em que $95 \%$ das UFAs afirmam ter espaço para organização do movimento estudantil, sendo que apenas 5\% afirmam não ter espaço. Numa sociedade em que a defesa da barbárie parece ganhar terreno e adesão entre os Estados Nacionais, principalmente naqueles países cuja dívida social é enorme e os altos índices de desigualdade social reclamam políticas sociais públicas e a garantia de direitos sociais tardiamente consolidados é extremamente significativo apoiarmos a organização política dos estudantes, uma vez que o Movimento Estudantil de Serviço Social (MESS) é um dos espaços histórico de resistência e luta da sociedade brasileira.

Com relação aos docentes, $79 \%$ das UFAs apresentam de 10 a 20 docentes, $13 \%$ de 21 a 25 docentes e $8 \% 10$ docentes. Cabe destacar ainda que todos os coordenadores de curso possuem formação em Serviço Social, conforme preconiza o Art. $5^{\circ}$ da Lei de Regulamentação da Profissão, que constituem atribuições privativas do assistente social:

$V$ - assumir, no magistério de Serviço Social tanto em nível de graduação como pós-graduação, disciplinas e funções que exijam conhecimentos próprios e adquiridos em curso de formação regular. 
VII - dirigir e coordenar Unidades de Ensino e cursos de Serviço Social, de graduação e pós-graduação.

O descumprimento da citada exigência também qualifica o exercício ilegal da profissão, estando os seus autores sujeitos às medidas administrativo-legais cabíveis.

No que tange a situação trabalhista dos docentes, $56 \%$ são celetistas, $34 \%$ cooperados, $8 \%$ funcionário público. Deste universo, 67\% são docentes-horistas com dedicação parcial e integral, $15 \%$ são apenas horistas e $8 \%$ possuem dedicação exclusiva. Os docentes também estão nas trincheiras de luta por melhores condições de trabalho e de reconhecimento, uma vez que as contratações funcionam de forma precária, os salários estão baseados em um número absurdo de horas-aula, com pouco incentivo para a pesquisa, o acúmulo intelectual e a dedicação aos estudos. Na formação profissional do assistente social, os docentes buscam construir resistências à medida que concretizam, diante de todas as adversidades assinaladas pela conjuntura, uma formação com potencialidade crítica, com capacidade para construir junto aos discentes uma consciência de classe.

O compromisso dos coordenadores e discentes também se expressa nas atividades culturais, de pesquisa e extensão. Todas as UFAs realizam Semanas Acadêmicas; $44 \%$ realizam Semanas Culturais e Acadêmicas, $65 \%$ possuem atividades de iniciação científica, $56 \%$ atividades de extensão e $44 \%$ monitorias. Tais atividades expressam conquistas políticas e pedagógicas, bem como refletem o protagonismo de coordenadores e discentes ao assegurar espaços de construção de conhecimento extraclasse, numa conjuntura marcada por exigências de profissionais técnicos e eficientes, sem uma formação que articule ensino-pesquisa e extensão. 


\section{Estágio Supervisionado}

O estágio supervisionado constitui-se como um espaço privilegiado da formação profissional, uma vez que a relação supervisor de campo/supervisor acadêmico/discente é construída com o objetivo de qualificar o processo de formação profissional. "O estágio é o lócus onde a identidade profissional do aluno é gerada, construída e referida; volta-se para o desenvolvimento de uma ação vivenciada, reflexiva e crítica e, por isso, deve ser planejado gradativamente e sistematicamente". (BURIOLLA, 2001, p. 13).

Nessa perspectiva, este espaço de formação profissional não se configura apenas por uma dimensão burocrática ou exigência acadêmica, mas pela sua natureza por meio da relação teórico/prática e a possibilidade de experienciar e refletir o exercício profissional, as relações de trabalho, o contato, a abordagem e a intervenção junto aos usuários; a troca de experiências com profissionais de Serviço Social e de outras áreas; a necessidade da dimensão ética; os desafios e potencialidades das políticas sociais e a materialidade das competências e atribuições profissionais.

Como está previsto nas Diretrizes Curriculares da ABEPSS o estágio é [...] uma atividade curricular obrigatória que se configura a partir da inserção do aluno no espaço socioinstitucional objetivando capacitá-lo para o exercício do trabalho profissional, o que pressupõe supervisão sistemática. Esta supervisão será feita pelo professor supervisor e pelo profissional do campo, por meio da reflexão, acompanhamento e sistematização com base em planos de estágio, elaborados em conjunto entre unidade de ensino e unidade campo de estágio, tendo como referência a Lei $n^{\circ}$ 8.662/93 (Lei de Regulamentação da Profissão) e o Código de Ética do Profissional (1993). O estágio supervisionado é concomitante ao período letivo escolar. (ABESS/CEDEPSS, 1997, p. 71). 
O cumprimento do estágio e o seu acompanhamento requer o organização da dimensão legal (Termos de Convênio e de Compromisso, Lei de Regulamentação da Profissão, Resolução CFESS 533/2008, Lei de Regulamentação do Estágio $n^{\circ}$ 11.788/2008) e político-pedagógica (Política de Estágio, Plano de Estágio, visitas aos campos de estágio, Supervisão Acadêmica e Fórum de Supervisores), no intuito de qualificar esse diálogo entre trabalho-formação profissional.

No que diz respeito a organização do estágio nas UFAs, $84 \%$ possuem Setor de Estágio, 8\% não possuem e 8\% estão em fase de construção. A carga horária prevista para a realização de estágio é de $15 \%$ do total da carga horária do curso, obedecendo o número mínimo de 3.000 horas para a organização total de disciplinas, oficinas, seminários temáticos e todos os espaços pedagógicos. Os dados da pesquisa revelam uma carga horária de 400-600 horas para realização de estágio, sendo que $66 \%$ da UFAs dispõem de $400-450$ horas, $18 \% 460-500$ horas, $4 \% 520$ horas e $4 \% 600$ horas.

A delimitação da quantidade de horas para o cumprimento do estágio supervisionado exige estratégias de acompanhamento político-pedagógico, sendo a Política de Estágio um documento legal e político que busca estabelecer diretrizes, princípios, atribuições, responsabilidades e competências para a realização do estágio e dos sujeitos que o protagonizam (discentes/supervisor de campo/supervisor acadêmico). As informações da pesquisa revelam que 97\% das UFAs possuem Política de Estágio e $3 \%$ estão em construção, o que revela a preocupação e compromisso com acompanhamento político-pedagógico do estágio supervisionado.

De acordo com as Diretrizes Curriculares e a Política Nacional de Estágio (PNE), construída coletiva pelas UFAs, discentes, docentes e supervisores de campo/acadêmico, sob a coordenação da ABEPSS, na gestão 2009-2010, “o estágio curricular obrigatório deve ser oferecido em diferentes níveis (totalizando entre dois e 
quatro semestres), distribuídos de forma equilibrada no decorrer dos últimos anos de integralização do curso. A carga horária das atividades de campo deve ser de, no máximo, 30 horas semanais (conforme Lei do Estágio), além da realização de, no mínimo, três horas/aula semanais de supervisão acadêmica” (PNE, 2010, p. 29).

As exigências para inserção no campo de estágio devem ser construídas analisando a organização dos componentes curriculares anteriores ao estágio, bem como aqueles que darão subsídio ao processo do estágio de supervisionado, tais como o debate da ética, dos fundamentos históricos, teórico-metodológicos do Serviço Social e da vida social. Recorrendo aos dados da pesquisa percebe-se que a maioria das UFAs (66\%) prevê a inserção do discente no campo de estágio para o $5^{\circ}$ semestre, $17 \%$ para o $4^{\circ}$ semestre, $13 \%$ para o $3^{\circ}$ semestre. Podemos inferir que as diferenças de semestre, no início do estágio, devem-se a dois fatores: 1) a organização curricular das UFAs previstas para sete semestre, exige a inserção do discentes no estágio supervisionado a partir do $4^{\circ}$ semestre ou 2) ao fato de que as UFAs que possuem sete ou oito semestre de formação começam a inserir o discente, a partir do $3^{\circ}$ ou $4^{\circ}$ semestre em estágio de observação.

Outra indicação importante da PNE (2010) diz respeito à criação e fortalecimento do Fórum de Supervisores, como espaço político e formativo de articulação entre as unidades de ensino e os supervisores de campo. Referendando o caráter estratégico do Fórum de Supervisores, a PNE apresenta como objetivo deste espaço aglutinar docentes e profissionais e estudantes em torno das questões do estágio, bem como garantir a qualificação desse lócus da formação profissional. Do total das UFAs participantes da pesquisa $74 \%$ possuem Fórum de Supervisores e $26 \%$ não possuem Fórum porque ainda não possuem discentes em estágio ou estão em processo de construção da Política de Estágio da unidade de ensino. 
A formação de natureza generalista em que o eixo central é a formar discente através de uma permanente construção de conteúdos, para intervir e analisar de forma crítica teórica/ética/política/cultural/metodologicamente nos processos sociais que legitimam a vida social remete a articulação do estágio supervisionado com os núcleos de fundamentação constitutivos da formação profissional e apresentado nas Diretrizes Curriculares. São eles: 1) Núcleo de fundamentos teórico-metodológicos da vida social; 2) Núcleo de fundamentos da particularidade da formação sociohistórica da sociedade brasileira; 3) Núcleo de fundamentos do trabalho profissional.

Esses núcleos não são excludentes e não podem ser trabalhados de forma dissociada, uma vez que eles possibilitam uma articulação entre os diversos componentes presentes na formação profissional, estando em sintonia com os pressupostos e os princípios do projeto profissional. O primeiro núcleo deve assegurar uma compreensão histórica do ser social, entendendo e situando-o no processo de constituição e desenvolvimento da sociedade burguesa, em que o trabalho é assumido como eixo central do processo de reprodução da vida social, da sociabilidade, da consciência, da universalidade e da capacidade de criar valores, escolhas e novas necessidades, fornecendo os componentes fundamentais da vida social que deverão ser trabalhados nos núcleos de fundamentação da realidade brasileira e do trabalho profissional.

O segundo núcleo objetiva analisar a constituição do Estado brasileiro, suas configurações e formação sociohistórica, os diferentes momentos conjunturais, os diversos projetos sociais em disputa. Trata-se, portanto, de apreender as relações entre Estado e sociedade nas diversas conjunturas, desvelando os mecanismos econômicos, políticos e institucionais criados, em especial as políticas sociais - que se constitui uma 
das mediações principais do exercício profissional do assistente social -, tanto no nível de seus objetivos, quanto na reprodução e manutenção dos antagonismos.

O núcleo do trabalho profissional considera a profissionalização do Serviço Social como uma especialização do trabalho, que tem nas múltiplas expressões da questão social o objeto definidor da sua prática profissional. Tal perspectiva permite articular a dimensão constitutiva do fazer profissional aos fundamentos históricos, teóricos e metodológicos necessários para apreender a formação teórica, política, social, cultural do trabalho profissional e, em particular, as formas de pensar dos assistentes sociais.

Assegurar esta lógica de organização curricular significa não só uma adesão teórica e política a uma formação com rigorosidade teórico-metodológica, crítica e propositiva, mas a compreensão de que

[...] a unidade entre teoria e prática não é um dado empírico mecânico, mas um devir histórico que sua base elementar e primitiva no sentimento de distinção, de separação, de independência quase instintiva, e que progride até a posse real e concreta de uma concepção de mundo coerente e unitária (GRAMSCI apud. GRUPPI, 1978, p. 72).

\section{OUTROS COMENTÁRIOS}

Partindo do entendimento de que "o Serviço Social só pode afirmar-se como prática institucionalizada e legitimada na sociedade, ao responder a necessidades sociais derivadas da prática histórica das classes sociais na produção e reprodução dos meios de vida e de trabalho de forma socialmente determinada," (IAMAMOTO, 1995, p. 16), torna-se imprescindível a criação de espaços acadêmicos, políticos, institucionais que priorizem a discussão acerca da profissão, das particularidades do caráter interventivo 
do assistente social, no sentido de fortalecer a construção de um projeto profissional, cuja direção social está pautada numa relação orgânica com o projeto das classes subalternas (YAZBEK, 1999, p. 30).

Numa sociedade em que a defesa da barbárie parece ganhar terreno e adesão e os altos índices de desigualdade social reclamam políticas sociais públicas e a garantia de direitos sociais tardiamente consolidados constitui um desafio de todos os que lutam pela justiça social e defende de forma intransigente os direitos humanos construir alternativas de resistências e confronto ao processo de dominação do capital, que conforme Meszáros (2002, p. 21) tem que se constituir de uma resposta universal, uma alternativa baseada na igualdade substantiva, "cuja ausência total é o denominador comum e o núcleo vicioso de todo esse sistema”.

Em tempo de alternativas privatistas para a questão social, de um Estado que reduz as intervenções no âmbito social e exige uma formação tecnicista e desprovida de qualquer atividade intelectual crítica, torna-se premente a afirmação do projeto profissional - suas lutas, defesas éticas, políticas e entidades profissionais - o direcionamento em que nele se faz para a luta de um outro projeto societário. Assim, torna-se indispensável que a formação profissional possa constituir-se em uma das objetivações da direção social estratégica que o Serviço Social vem construindo e lutando, nos últimos 30 anos, e que é tão caro aos sujeitos profissionais e organização política da classe trabalhadora. 


\begin{abstract}
The research "Mapping of Academic Unities of Formation - UFAs II South Region", held by the Brazilian Association of Education and Research in Social Work (ABEPSS), the management from 2009 to 2010, shows the intention to understand the particularities of the training of social workers, with respect to the profile of UFAs, curricular organization, the relationship with ABEPSS, the supervised training, research and strategies for the affirmation of the curriculum guidelines in the professional training. Grasp the particularities of the profession, professional education and practice, articulating them necessarily to historical factors on which they are inserted, it becomes a condition for the affirmation of professional design, its principles, values and struggles, as well as for the claim the social significance of professional expertise as a collective work, which objective of intervention the multiple expressions of social issues and the individuals who live with the exploitation, injustice and denial of human dignity.
\end{abstract}

KEYWORDS: Professional Training, Curriculum Guidelines, Professional, Social Work

\title{
REFERÊNCIAS BIBLIOGRÁFICAS
}

ABEPSS. Diretrizes Gerais para o curso de Serviço Social (Texto na íntegra aprovado em assembleia, em novembro de 1996). Rio de Janeiro, 1996.

. CEDEPSS. Diretrizes gerais para o curso de Serviço Social. Cadernos ABESS, n 7. São Paulo: Cortez, 1997.

. Revista Temporalis "Reforma do Ensino Superior e Serviço Social”. Ano I, n 1, Brasília: janeiro a junho de 2000.

. Textos e Documentos. Ano 2, suplemento (out. 2001). Brasília: Grafline, 2001.

ABESS. Diretrizes Curriculares do Curso de Serviço Social: sobre o processo de implementação. Ano VII, n 14 (jul./dez.2007). Brasília: ABEPSS, 2007.

Revista Serviço Social \& Saúde. UNICAMP Campinas, v. X, n. 11, Jul. 2011 
. Política Nacional de Estágio. Rio de Janeiro, 2010.

ABRAMIDES, M. B. C. O ensino do trabalho profissional: o estágio na formação profissional. Palestra proferida na Oficina da Região Sul II - Gestão 2003-2004. São Paulo: ABEPSS, 2003.

BRASIL. Lei $\mathbf{n}^{\mathbf{0}} \mathbf{1 1 . 7 8 8}$, de 25 de setembro de 2008, que dispõe sobre o estágio de estudantes e dá outras providências. Publicado no D.O.U. de 26/09/2008.

. Lei $\mathbf{n}^{\circ} \mathbf{8 . 6 6 2}$, de 7 de junho de 1993, que dispõe sobre a profissão de Assistente Social e dá outras providências. CRESS, Porto Alegre, 1996.

CHAUÍ, M. Convite a Filosofia. São Paulo: Ática, 2004.

Escritos sobre a universidade. São Paulo: Editora UNESP, 2001.

GENTILI, P. , SILVA, T. T. da (Orgs.). Escola S.A. Quem ganha e quem perde no mercado educacional do neoliberalismo. Brasília: CNTE, 1996, p. 20-1.

GRUPPI, L. O Conceito de hegemonia em Gramsci. Rio de Janeiro: Editora Graal, 1978.

IAMAMOTO, M.V. O Serviço Social na contemporaneidade: trabalho e formação profissional. São Paulo: Cortez, 1998.

. Formação do assistente social no Brasil e a consolidação do projeto éticopolítico. Revista Serviço Social \& Sociedade. N. 79. São Paulo: Cortez, 2004. . Serviço Social em tempo de capital fetiche. São Paulo: Cortez, 2007.

MESZAROS, I. Século XXI: Socialismo ou Barbárie. São Paulo: Boitempo, 2003.

YAZBEK, C. Os fundamentos do Serviço Social na contemporaneidade. In: Capacitação em Serviço Social e Política Social. Mód. 04. Brasília: UNB, 2000. 